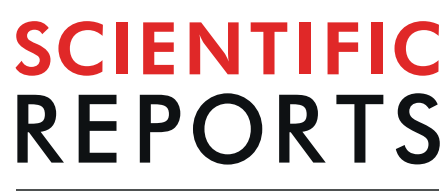

natureresearch

\title{
Innovation in wild Barbary macaques (Macaca sylvanus)
}

\author{
Federica Amici ${ }^{1,2^{*}}$, Alvaro L. Caicoya ${ }^{3}$, Bonaventura Majolo ${ }^{4}$ \& Anja Widdig ${ }^{1,2}$
}

Innovation is the ability to solve novel problems or find novel solutions to familiar problems, and it is known to affect fitness in both human and non-human animals. In primates, innovation has been mostly studied in captivity, although differences in living conditions may affect individuals' ability to innovate. Here, we tested innovation in a wild group of Barbary macaques (Macaca sylvanus). In four different conditions, we presented the group with several identical foraging boxes containing food. To understand which individual characteristics and behavioural strategies best predicted innovation rate, we measured the identity of the individuals manipulating the boxes and retrieving the food, and their behaviour during the task. Our results showed that success in the novel task was mainly affected by the experimental contingencies and the behavioural strategies used during the task. Individuals were more successful in the 1-step conditions, if they participated in more trials, showed little latency to approach the boxes and mainly manipulated functional parts of the box. In contrast, we found no effect of inhibition, social facilitation and individual characteristics like sex, age, rank, centrality, neophobia and reaction to humans, on the individuals' ability to innovate.

Innovation has been defined as the solution to a novel problem, or the novel solution to a familiar problem ${ }^{1,2}$. In humans, the ability to innovate and socially transmit innovations has been crucial through evolution, allowing us to reach a unique level of behavioural and cultural complexity ${ }^{3,4}$. However, innovation also provides a variety of benefits to other animals, allowing them to develop novel responses against predators, exploit novel resources and invade new niches ${ }^{1,5-15}$. By allowing individuals to better cope with novel socio-ecological challenges, innovation is thought to provide direct fitness benefits, especially in dynamic environments ${ }^{1,2,9,10,12,13,16,17}$

The ability to innovate is therefore widespread across taxa. Several species of birds, fish, carnivores and rodents, just to name a few, show evidence of innovation ${ }^{2,18,19}$ for reviews. Studies in captivity have also shown that some primate species are excellent problem-solvers ${ }^{20-27}$. Great apes, for instance, can use several new solutions to extract food from a container, inhibiting old strategies when they become inefficient ${ }^{24}$. When presented with a novel foraging task, great apes could successfully move food through a maze, planning up to two steps ahead to avoid food falling into traps ${ }^{28}$. Even lemurs (Varecia spp.) and callitrichid monkeys (Leontopithecus spp., Saguinus spp., Callithrix spp.), who are phylogenetically more distant from humans and have relatively small brain sizes ${ }^{29}$, can solve novel foraging tasks by retrieving food from different containers ${ }^{21}$.

Apart from inter-specific differences, there are also several intra-specific differences in terms of innovation. Traditionally, these differences have been explained by the Innovation by Necessity and the Free Time hypothe$\operatorname{ses}^{2,30-32}$. The Innovation by Necessity hypothesis (also called Bad Competitor hypotheses ${ }^{18}$ ), in particular, predicts that innovation is especially frequent in those individuals who would otherwise have no access to food, and thus need to take the risk of performing potentially dangerous novel behaviours as a last resort ${ }^{2,31,32}$. According to this hypothesis, better innovators would be individuals in bad physical condition, lower-ranking or younger, and in species with sexual dimorphism, individuals of the smaller sex (e.g. birds ${ }^{13}$ and primates ${ }^{33,34}$ ). In contrast, the Free Time hypothesis (also called the Excess of Energy hypothesis ${ }^{18}$ ) predicts that innovation is more frequent when individuals are fit and healthy, and have more time and energy to devote to innovation ${ }^{30}$. Therefore, innovation should be more frequent in higher-ranking animals, younger individuals and animals of the larger sex (e.g. birds $^{35-37}$, carnivores $^{38,39}$ and primates $\left.{ }^{40,41}\right)$.

Moreover, sociality may increase fitness and be positively linked to innovation. Strong and enduring social relationships, for instance, play a crucial role in animal life, and predict individual fitness in both human ${ }^{42,43}$ and

${ }^{1}$ Behavioral Ecology Research Group, Institute of Biology, Faculty of Life Science, University of Leipzig, Leipzig, Germany. ${ }^{2}$ Research Group Primate Behavioural Ecology, Department of Human Behavior, Ecology and Culture, Max-Planck Institute for Evolutionary Anthropology, Leipzig, Germany. ${ }^{3}$ Department of Clinical Psychology and Psychobiology, Faculty of Psychology, University of Barcelona, Barcelona, Spain. ${ }^{4}$ School of Psychology, University of Lincoln, Lincoln, United Kingdom. *email: amici@eva.mpg.de 
non-human primates ${ }^{4-49}$. It is therefore possible that individuals having many social interactions, or those who are "social hubs" in the group ${ }^{50}$, may be more fit and prone to take the risks linked to innovation, as they can count on extended social support (in line with the Free Time hypothesis). In theory, it is also possible that more innovative individuals increase their prestige or status through the implementation of novel solutions, so that they are preferred over other social partners ${ }^{51,52}$. In both cases, high sociality could be predictive of individual innovation rate. In line with the Innovation by Necessity hypothesis, in contrast, low sociality would imply lower individual fitness, and thus higher innovation rate.

A recent meta-analysis on innovation in mammals and birds ${ }^{18}$, showed that individuals of the larger sex innovate more than those of the smaller sex, supporting the Free Time hypothesis; none of the other factors proposed by the Innovation by Necessity and the Free Time hypotheses predicted innovation. Therefore, it is likely that factors other than sex, age, rank or physical condition may more reliably predict the distribution of innovation. For example, individuals strongly differ in their tendency to avoid or approach novel objects (i.e. neophobia or neophilia, respectively), which may clearly affect their participation in novel tasks and their ability to solve novel problems $s^{20,39,53-60}$. Response to novelty usually correlates across different contexts ${ }^{60-63}$, and researchers rely on different methods to assess it (e.g., reaction to novel objects, food or environments).

Similarly, some individuals are more persistent than others, spending more time interacting with and attempting to solve novel tasks ${ }^{19}$. Individuals also differ in the variety of exploratory behaviours shown when interacting with the novel task, and in the number of objects or parts of the objects manipulated ${ }^{18}$. These differences in persistence and exploration have been shown to affect innovation ${ }^{2,19,20,38,39,53,56,59}$. In orangutans (Pongo pygmaeus and $P$. abelii), for instance, the ability to solve novel problems is especially high for individuals who are highly explorative, and show a positive response to novel objects and humans ${ }^{64}$.

To date, the majority of experimental studies on innovation has been conducted in captivity, where controlled conditions are often easier to implement. In the wild, innovation has been mainly studied by conducting observations to find instances of novel behaviours ${ }^{65-68}$. However, innovations in the wild are more sporadic and less predictable, and very infrequent behaviours might be wrongly classified as innovations simply because they had never been observed before ${ }^{1,2,69,70}$. An alternative approach is thus to study wild animals with novel experimental tasks. Some studies have successfully implemented this experimental approach, testing innovative behaviour in different species of wild birds ${ }^{36,60,71-74}$ and carnivores ${ }^{38,75}$. To our knowledge, however, such an experimental approach to the study of innovation has only been used twice in primates. Huebner and Fichtel ${ }^{76}$ tested wild red-fronted lemurs (Eulemur rufifrons) on a foraging box that could be opened in three different ways. As soon as one solution had been mastered, it was blocked and individuals had to invent another one, inhibiting the previously learned strategy. In this study, most individuals interacted with the boxes, and the best innovators were adults and more explorative individuals ${ }^{76}$. In another study, Laidre ${ }^{40}$ presented a group of baboons (Papio anubis) with three different novel tasks, in which individuals could access out-of-reach food by either (i) pulling a string attached to bananas, (ii) dipping with sticks in a metal tube, or (iii) using a stick to push food out of a metal conduit. Baboons could only solve the first task, and failed with the other two even when the sticks had been already positioned in the correct position to facilitate solution of the task.

These results contrast with those on captive primates, and suggest that captive individuals may be more innovative than their wild counterparts (in birds ${ }^{36,60,77}$ and hyenas ${ }^{39}$ ). In captivity, animals experience atypical living conditions, which may affect the development of their cognitive skills ${ }^{1,60,77-79}$. Continuous exposure to the human cultural milieu and to novel objects, in particular, may provide captive individuals with more chances to understand the physical properties of objects and their potential function as tools ${ }^{40,80,81}$, or even simply reduce their neophobia toward humans and experimental set-ups ${ }^{56,64,82-84}$. Therefore, collecting more information on wild primates, by testing them in their social groups under natural conditions, appears a necessary step to understand how the ability to innovate really varies across conspecific individuals and to assess whether the same evolutionary pressures are at play across different taxa.

In this study, we aimed to test innovation in a wild group of Barbary macaques (Macaca sylvanus). In four different conditions, we presented the study animals with several identical foraging boxes. In each condition, individuals had only one way to open the box. While non-functional parts of the boxes were completely transparent, functional parts were coloured green across all conditions. We then measured the identity of the individuals participating and solving the novel task, and their behaviour during the task (i.e. latency to interact with the box, time spent manipulating non-functional and functional parts of the boxes, and number of attempts to reach the food through the transparent plexiglas). We further measured individual levels of neophobia while feeding on novel food, and conducted behavioural observations to assess individual rank, position in the social network and reaction to humans. We then analysed whether innovation rate was affected by the individual behaviour during the task (as defined above), and whether individual characteristics (i.e. sex, age, rank, neophobia, position in the social network and reaction to humans) affected innovation rate and behaviour during the task. Detailed predictions are summarized in Table 1.

\section{Methods}

Subjects. We studied 19 Barbary macaques (Macaca sylvanus) living in a free-ranging group in Gibraltar. The group included males and females of different age classes and rank (see Table 2 for more details). The monkeys lived in an area characterized by steep cliffs and sparse vegetation, in a military zone where tourists and inhabitants have no access. The group foraged in the area, but was also partially provisioned with small quantities of fruit and vegetables every morning, which covered a limited part of their diets. In this way, macaques still had to forage, but they limited their incursions in the village to search for food.

Materials and procedures. Between October 2017 and March 2018, we conducted behavioural observations on all adults and subadults in the group, whilst no experiment was administered. Firstly, we used the Elo 


\begin{tabular}{|l|l|l|l|l|l|l|l|l|l|l|}
\hline Hypotheses & Sex & Age & Rank & Centrality & Neophobia & $\begin{array}{l}\text { Reaction to } \\
\text { humans }\end{array}$ & Latency & Exploration & $\begin{array}{l}\text { Functional } \\
\text { manipulations }\end{array}$ & Inhibition \\
\hline Free Time & Males & Young & High & High & & & & & & \\
\hline $\begin{array}{l}\text { Social } \\
\text { fnnovation by } \\
\text { Necessity }\end{array}$ & Females & Young & Low & Low & & & & & & \\
\hline Personality & & & & & Low & Positive & & & & \\
\hline Behaviour & & & & & & & Low & High & High & High \\
\hline
\end{tabular}

Table 1. Predictions about the individual characteristics and behaviours which might predict success in the innovation task by the wild Barbary macaques we tested (predictions confirmed by our results are in bold).

\begin{tabular}{|c|c|c|c|c|c|c|c|c|}
\hline Subject & Sex & Age class & Elo-rank & RH & Neophobia & Centrality & Strength & Trials \\
\hline Batmana & female & adult & 0.53 & 2 & 0.50 & 0.47 & 24 & 8 \\
\hline Chicho & male & juvenile & 0.69 & 2 & 0.48 & 0.90 & 41 & 97 \\
\hline Colega & male & adult & 0.22 & 2 & 0.67 & 0.65 & 30 & 9 \\
\hline Gruñon & male & adult & 0.67 & 3 & 0.48 & 0.38 & 18 & 27 \\
\hline Jefa & female & adult & 0.60 & 3 & 0.50 & 0.72 & 34 & 18 \\
\hline Legolashijo & male & adult & 0.51 & 3 & 1.00 & 0.20 & 7 & 0 \\
\hline Legolaspadre & male & adult & 0.77 & 2 & 0.47 & 0.93 & 41 & 10 \\
\hline Mamabebeenano & female & adult & 0.00 & 4 & 0.45 & 0.66 & 32 & 3 \\
\hline Mamanoel & female & adult & 0.76 & 2 & 0.60 & 0.54 & 26 & 37 \\
\hline Mancha & female & adult & 0.58 & 3 & 0.50 & 0.15 & 7 & 0 \\
\hline Mephisto & male & adult & 0.88 & 3 & 0.54 & 0.59 & 27 & 17 \\
\hline Nerd & female & adult & 0.25 & 4 & 0.50 & 0.09 & 4 & 23 \\
\hline Noruega & female & adult & 0.48 & 3 & 0.37 & 0.80 & 40 & 36 \\
\hline Orejacortada & female & adult & 0.37 & 1 & 0.64 & 0.75 & 35 & 13 \\
\hline Paul & male & adult & 1.00 & 3 & 0.48 & 1.00 & 49 & 21 \\
\hline Pedro & male & juvenile & 0.39 & 2 & 0.50 & 0.71 & 33 & 13 \\
\hline Pendiente & male & adult & 0.11 & 4 & 1.00 & 0.31 & 15 & 0 \\
\hline Tetas & female & adult & 0.06 & 4 & 0.40 & 0.33 & 16 & 19 \\
\hline Uniteta & female & adult & 0.51 & 3 & 0.61 & 0.52 & 23 & 45 \\
\hline
\end{tabular}

Table 2. List of the wild Barbary macaques located in Gibraltar and participating in the study. We classified as adults all females estimated to be above 5 and all males above 6 , while juveniles where individuals between 1 and 3 years of age. One corresponds to a high rank, a positive reaction to humans (RH), and high neophobia. More central individuals and individuals with higher strength have higher values. Trials indicated the number of trials in which individuals participated. In bold, individuals who retrieved food in at least one trial.

method to determine the dominance hierarchy (EloRating package, version 0.43 ), based on all dyadic agonistic interactions with a clear winner-loser outcome, recorded via all occurrence sampling ${ }^{85}$. The analyses were run over 125 interactions to obtain the individual scaled Elo-rank (see Table 2), which was highly stable (0.992) over the study period.

We further determined the social network based on hourly scans of the group, in which we recorded the spatially closest partner of each individual. We then used these measures to build an undirected weighted matrix and run social network analyses, using the following packages in R: vegan (version 2.5-3) ${ }^{86}$, asnipe (version 1.1.10) ${ }^{87}$, and igraph (version 1.2.1) ${ }^{88}$. Social network analyses assessed individuals' Eigenvector centrality (i.e. the sum of the centralities of an individual's neighbours, a measure of the importance of each individual "as a social hub") and strength (i.e. the sum of all edge weights connected to the node, which represents the expected total interaction rate for each individual ${ }^{50,89}$; see Table 2; Fig. 1). As Eigenvector centrality and strength were correlated, only centrality was used in the analyses (see below).

During the first weeks of observations, the Experimenter (A.L.C.) also assessed monkeys' reaction to a novel human, by adapting the human orientation test described by Damerius and colleagues ${ }^{64}$. In particular, the Experimenter estimated the individual reaction to a novel human by attributing each individual a value from 1 to 5, based on the monkey's reaction to the Experimenter, when he approached them in the first days of the habituation ( 1 being a very positive reaction, e.g. maintaining proximity and lip-smacking to the Experimenter; 3 being a neutral reaction, e.g. resting or moving calmly; and 5 being a very negative reaction, e.g. quickly fleeing and showing aggressive behaviours toward the Experimenter).

We further assessed neophobia levels with a specific task. We prepared a testing arena of $4 \times 4$ meters, dividing it into 4 identical squares marked with stones (see Fig. 2). Inside this arena, we distributed 8 slices of banana. In the first condition, we distributed 2 banana slices per square, half of them having been previously dyed with blue colour. By monitoring the reaction to novel coloured food (as compared to familiar non-coloured food), we could 


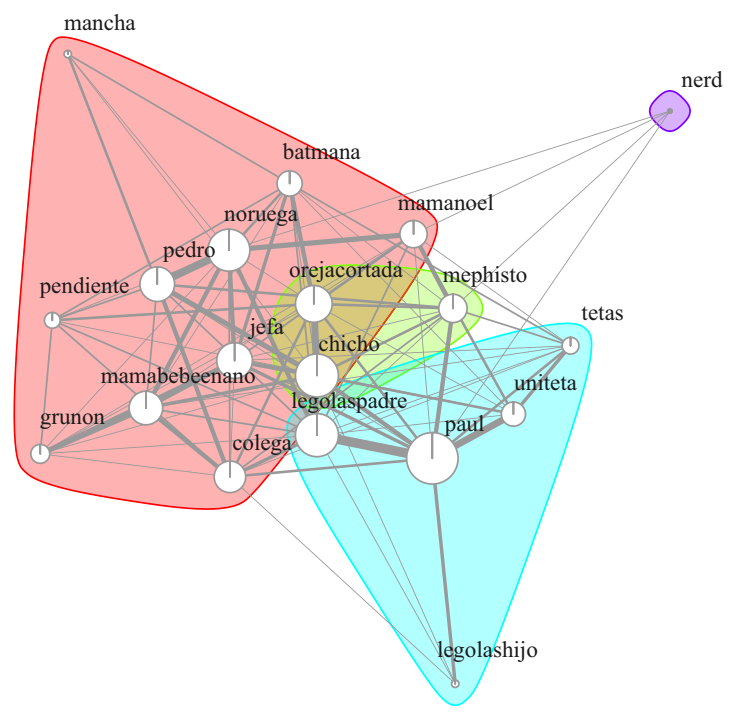

Figure 1. Social network of the group of wild Barbary macaques located in Gibraltar and participating in this study. Weighted edges and nodes are proportional to the individual strength in the network (i.e. the sum of all edge weights connected to the node). Communities are shown with different colours (see Farine \& Whitehead ${ }^{89}$ ). Social network analyses (and the resulting Fig. 1) were run in R, using the vegan (version 2.5-3), asnipe (version 1.1.10) and igraph (version 1.2.1) packages (Oksanen et al ${ }^{86}$; Farine ${ }^{87}$; Csardi \& Nepusz ${ }^{88}$ ).
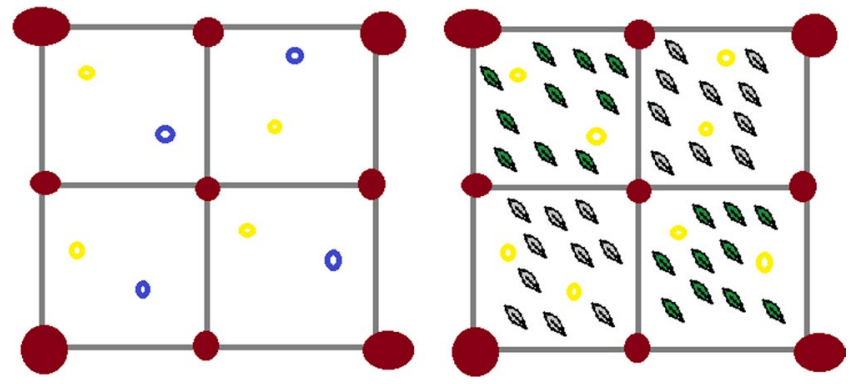

Figure 2. Set-up of the neophobia task administered to the wild group of Barbary macaques tested in Gibraltar. The full ovals represent stones. On the left, set-up for the first and second conditions of the neophobia task. The light/yellow empty ovals represent banana slices, and the dark/blue empty circles represent blue- (in the first condition) or red-dyed (in the second condition) banana slices. On the right, set-up for the third and fourth conditions of the neophobia task. The dark/green rhombs represent local leaves, and the light/silver rhombs represent silver (in the third condition) or yellow (in the fourth condition) pieces of salt-dough.

assess individual neophobic levels. In particular, we operationalized neophobia as the number of familiar food items eaten, out of the total number of food items eaten by the individual (i.e. a value closer to 1 indicate more neophobia). The second condition was identical to the first one, but food was dyed with a different colour (i.e., red). In the third condition, we distributed 2 banana slices per square, with two non-adjacent squares having been first covered with local leaves, and the 2 other squares having been covered with silver pieces of salt-dough, looking like leaves. We monitored the reaction to novel objects (as compared to familiar leaves), by operationalizing neophobia as the number of food items eaten from the squares with leaves, out of the total number of food items eaten by the individual. The fourth condition was identical to the third one, but pieces of salt-dough were painted yellow. We ran 20 sessions for each of the four conditions. As soon as the banana slices had been positioned in the arena, we video-recorded and later coded all the individuals entering the testing arena and retrieving food, specifying the colour of the food retrieved (i.e. dyed or not), or the position (i.e. square with leaves or salt-dough). Individual levels of neophobia are summarized in Table 2. Please note that food colour had no odour and no taste.

The innovation task was administered after the neophobia task and consisted of four different conditions (see Fig. 3). In each condition, up to three identical boxes (approximately $40 \times 40 \times 40 \mathrm{~cm}$ ) were tied to poles, approximately $1.5 \mathrm{~m}$ from each other, for several consecutive days (up to two hours a day). The presence and position of several identical boxes prevented complete monopolization by higher-ranking individuals. All boxes were baited with a highly liked food reward (i.e. a peanut). We considered a trial to start when one individual (i.e. the subject) came within $1 \mathrm{~m}$ of a box, except if (i) the box had already been emptied by another individual and not yet refilled, or (ii) the individual approached the box from the back (so that it was impossible to interact with the box in any way). A trial was considered to end if the individual retrieved the food or left the box (i.e. went further 


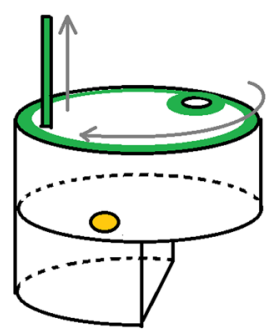

a. Condition 1

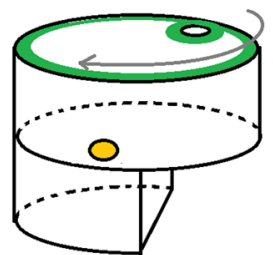

b. Condition 2

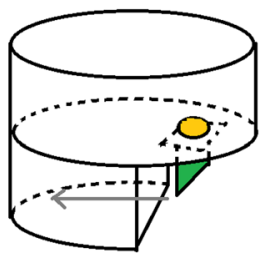

c. Condition 3

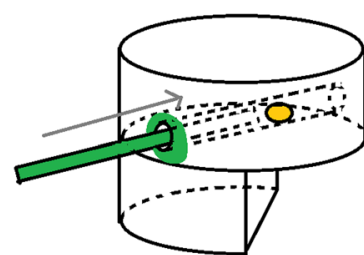

d. Condition 4

Figure 3. Set-up of the innovation task administered to the wild group of Barbary macaques in Gibraltar, for (a) Condition 1, (b) Condition 2, (c) Condition 3 and (d) Condition 4. The light grey/yellow full oval represents food. Dark grey/green parts represent the functional parts of the boxes. Grey arrows represent the movements needed to access the food in the four conditions.

than $1 \mathrm{~m}$ from the box). No effort was made to control which individuals approached the boxes and participated in the tasks ${ }^{40}$. In all conditions, the foraging box was completely transparent (so that food was visible), with the exception of the green functional parts (i.e. the peg, lid, tab or stick, depending on the condition; see Thornton \& Samson, 2012, for a similar apparatus).

In the first condition, food could be accessed through a 2-step procedure, by first removing a peg, and then rotating the green upper lid. In this way, the upper hole aligned to the food inside the box, and the subject could retrieve the food (Fig. 3a). After 41 trials, however, none of the individuals could successfully remove the peg. Therefore, all the following conditions were run without the peg, and food could be accessed with a 1-step procedure. In the second condition, subjects had to rotate the green upper lid, as above, to retrieve the food (Fig. 3b). In the third condition, food could be accessed by pulling a little tab, so that food would fall out of the box (Fig. 3c). In the fourth condition, food could be accessed by pushing it out of a green cylinder with a stick (Fig. 3d). To facilitate the solution of the task, the stick had been partially inserted in the tube. All actions required to solve the task (i.e. sliding, pulling and pushing) belong to the natural behavioural repertoire of the species, and prior habitual tool use was not a prerequisite to solve these tasks ${ }^{40,75}$. For each condition, we ran a total of $41,94,125$ and 136 trials, respectively. As trials were opportunistically run by placing the boxes in the group, the number of trials differed across conditions.

All experimental protocols were discussed and approved by the Helping Hand Trust in Gibraltar, which allowed us access to the macaques. The procedures were also approved by the ethics committees of La Montagne des Singes (Kintzheim, France), the Nürnberg Zoo (Germany) and the Kyoto University (Japan). All methods were carried out in accordance with the national regulations of the country in which the study took place.

Coding and statistical analyses. All trials were video-recorded with two video-cameras, one providing an overview of all the boxes, and the other one a close-up image of each foraging box. By watching all the videos, we later coded the identity of each subject participating in a trial, trial duration, whether the subject retrieved the food, time spent manipulating functional and non-functional parts of the box (as a measure of exploration), and proportion of time spent manipulating only functional parts of the box (to assess whether manipulations mainly implied functional actions, or rather a mix of functional and non-functional actions as in trial-and-error strategies). We further coded the number of attempts made by the subject to try and directly reach for food through the transparent plexiglas (as a measure of inhibition), and latency to touch the box for the first time (measured from the beginning of the trial, i.e. from the moment the subject came within $1 \mathrm{~m}$ of a box, until the subject touched the box). If the subject never approached the box during the trial, latency was considered as the total duration of the trial (i.e., from the moment the subject came within $1 \mathrm{~m}$ of the box, until the subject left). No latency measures were taken for subjects who did not come within $1 \mathrm{~m}$ of a box. Finally, we noted whether other individuals were present (i.e. within $1 \mathrm{~m}$ from the boxes) to test whether the presence of conspecifics facilitated the solution of the task. A second observer blind to the hypotheses of the study re-coded $20 \%$ of all the trials to assess individuals' success, latency to approach the box, exploration, manipulation of functional parts of the box, inhibition and presence of other individuals at the boxes. Inter-observer reliability was very good (for success, inhibition and presence of others, $\mathrm{N}=79$, and Cohen's $\kappa=1, \kappa=0.681$ and $\kappa=0.883$, respectively; for latency, exploration and functional manipulation, $p<0.001$, and $r_{s}=0.992, r_{s}=0.998$ and $r_{s}=0.923$, respectively).

Analyses were conducted using multilevel-ordered logit models, always including a varying intercept by subject identity to correct for repeated observations. A first set of models assessed the factors affecting variation in the ability to obtain food from the novel foraging boxes. We compared a null intercept-only model (M1.0) to models obtained by adding individual characteristics (i.e. sex, age and rank: M1.1; or centrality, neophobia and reaction to humans: M1.2), measures of the individual behaviour during the task (i.e. latency to approach the box: M1.3; exploration of the box: M1.4; manipulation of the functional parts of the box: M1.5; inhibition: M1.6; presence of others at the boxes: M1.7), or experimental contingencies (i.e. experimental condition and number of trials in which the individual participated: M1.8) as fixed effects (see Table 1). In all models, fixed effects were not correlated. 


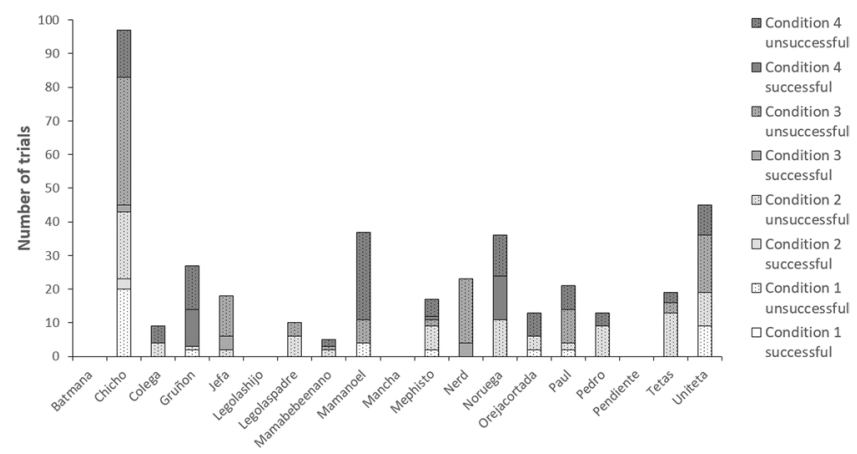

Figure 4. For each individual in the group of wild Barbary macaques tested in Gibraltar, number of trials in which the subject participated and obtained the food, in each of the four conditions.

Given the relatively small sample size, statistical analyses were run with a Bayesian approach, using the rethinking package ${ }^{90}$ in $\mathrm{R}$ (version 3.2.3). In all models, we used weakly informative priors and estimated parameters with RStan ${ }^{91}$, running 3 Hamiltonian Monte Carlo chains in parallel (with 10000 samples, half of which were warm-up samples). Convergence was suggested by a high effective number of samples (always $\geq 1878$ ) and Rhat estimates of $1.00^{90}$. We then selected models based on the lowest Widely Applicable Information Criteria (WAIC, a measure of sample deviance), and further calculated Akaike weights to estimate the relative probability that different models will best predict future data.

If the selected best models included measures of individual behaviour (i.e. latency to approach the box, exploration of the box, manipulation of its functional parts, inhibition or presence of others near the boxes), a further set of models was run to assess whether the behaviour shown in the task was in turn affected by the individual characteristics of the subject (i.e. sex, age and rank: M2.1/M3.1; or centrality, neophobia and reaction to humans: M2.2/3.2). We then compared this second set of models to a null intercept-only model (M2.0/M3.0; see Table 1). Finally, we assessed whether individual performance was consistent across conditions (i.e. whether subjects who were more successful in one condition were also more successful in the other conditions). We therefore ran Spearman correlations between the individual proportion of successful trials in conditions 2-3, 2-4 and 3-4.

\section{Results}

Out of the 19 individuals in the group, 15 participated in at least one of the conditions. Of these 15 individuals, only 6 individuals solved the task at least once (see Table 2; Fig. 4). The proportion of successful trials by each individual did not correlate across conditions (Conditions 2-3: $\mathrm{N}=19, r_{s},=0.474, p=0.164$; Conditions 2-4: $\mathrm{N}=19, r_{s},=-0.102, p=1.000$; Conditions 3-4: $\mathrm{N}=19, r_{s},=-0.186, p=0.874$ ).

In set 1 , we compared different models to assess which factors affect individuals' ability to obtain food from the novel foraging boxes. M1.8, M1.5 and M1.3 had the lowest WAIC and the highest model weight $(0.47,0.26$ and 0.22 , respectively), showing that experimental contingencies (M1.8), manipulation of the functional parts of the box (M1.5) and latency to approach the box (M1.3) all contributed to the model fit (see Table 3; Fig. 5a-c), while the other fixed effects only had a very marginal effect (i.e. exploration; sex, age, rank; centrality, neophobia and reaction to humans) or no effect at all (i.e. inhibition; presence of others at the boxes). In particular, performance varied across conditions, with probability of success being lower in Condition 1 than in all the other conditions. Participating in a higher number of trials also slightly but positively affected performance (M1.8: $\beta=0.07$, $89 \%$ Prediction Interval $[\mathrm{PI}]=0.02$ to 0.12 ). Moreover, better performance in the innovation task was predicted by a higher proportion of functional manipulations (M1.5: $\beta=1.43,89 \% \mathrm{PI}=0.44$ to 2.45$)$, and by a lower latency during the task (M1.3: $\beta=-0.26,89 \% \mathrm{PI}=-0.40$ to -0.10$)$.

We therefore ran two further sets of models, with latency to approach and functional manipulation of the box as dependent variables in set 2 and 3, respectively. In set 2, the WAIC was highest in M2.3, and slightly lower in M2.0 than in M2.1 (see Table 3; Fig. 5d,e). As the model weight was high in both M2.0 and M2.1 (0.52 and 0.43, respectively), we examined the estimates of both models. In M2.1, sex appeared to play the main effect on latency, with males having a higher latency than females $(\beta=8.37,89 \% \mathrm{PI}=0.15$ to 16.71$)$. In set 3 , the WAIC was highest in M3.1, and lower in M3.0 than M3.2 (see Table 3; Fig. 5f,g). As both M3.0 and M3.2 had a high weight (0.52 and 0.36 , respectively), however, both models were examined. The model estimates in M3.2, however, suggested that centrality and reaction to humans had no clear effect on the proportion of time spent in functional manipulations of the boxes.

\section{Discussion}

In this study, we investigated inter-individual differences in innovation in a wild population of Barbary macaques. Although most individuals participated in the task, only few were successful, with no consistency across tasks. In particular, success in the novel task was mainly affected by the experimental contingencies and the behavioural strategies used during the task. Individuals were more successful in the 1-step conditions, if they participated in more trials, showed little latency to approach the boxes and mainly manipulated functional parts of the box. In contrast, individual characteristics of the subjects (i.e. sex, age, rank, centrality, neophobia and reaction to humans), as well as inhibition and presence of others at the boxes had little to no effect on the individuals' ability to innovate. 


\begin{tabular}{|c|c|c|c|c|c|c|c|c|}
\hline Set & Model & Fixed effects included & WAIC & pWAIC & dWAIC & weight & SE & dSE \\
\hline \multirow{9}{*}{1} & M1.8 & Condition, number of trials & 197.6 & 8.2 & 0.0 & 0.47 & 21.68 & NA \\
\hline & M1.5 & Functional manipulation & 198.8 & 7.6 & 1.2 & 0.26 & 19.68 & 6.78 \\
\hline & M1.3 & Latency to approach & 199.2 & 8.9 & 1.5 & 0.22 & 22.35 & 9.65 \\
\hline & M1.4 & Exploration & 204.7 & 7.9 & 7.0 & 0.01 & 21.85 & 4.93 \\
\hline & M1.2 & Centrality, neophobia, RH & 205.3 & 7.6 & 7.7 & 0.01 & 22.05 & 4.54 \\
\hline & M1.1 & Sex, age, rank & 205.6 & 7.6 & 8.0 & 0.01 & 21.81 & 4.63 \\
\hline & M1.0 & - & 206.6 & 7.2 & 8.9 & 0.01 & 21.46 & 4.49 \\
\hline & M1.7 & Presence of others at the box & 208.1 & 8.0 & 10.4 & 0.00 & 21.86 & 4.72 \\
\hline & M1.6 & Inhibition & 208.7 & 8.1 & 11.0 & 0.00 & 22.01 & 4.20 \\
\hline \multirow[t]{3}{*}{2} & M2.0 & - & 3781.6 & 79.8 & 0.0 & 0.52 & 320.10 & NA \\
\hline & M2.1 & Sex, age, rank & 3781.9 & 78.6 & 0.4 & 0.43 & 318.47 & 2.28 \\
\hline & M2.2 & Centrality, neophobia, RH & 3786.3 & 80.4 & 4.7 & 0.05 & 323.80 & 3.80 \\
\hline \multirow[t]{3}{*}{3} & M3.0 & - & -69.2 & 12.9 & 0.0 & 0.52 & 38.69 & NA \\
\hline & M3.2 & Centrality, neophobia, RH & -68.5 & 13.9 & 0.7 & 0.36 & 38.54 & 1.35 \\
\hline & M3.1 & Sex, age, rank & -66.3 & 14.3 & 2.9 & 0.12 & 38.32 & 2.05 \\
\hline
\end{tabular}

Table 3. Sets of models, ordered with the smallest WAIC (Widely Applicable Information Criteria) first. Each set of models has the same dependent variable (i.e., success in the innovation task in set 1, latency to approach the box in set 2, and proportion of functional manipulations in set 3 ). The best models in each set are presented in bold. For each model, we present the fixed effects included (apart from the intercept and an intercept by subject identity, which were included in all models), WAIC, estimated effective number of parameters, relative difference with the WAIC for the top-ranked model, Akaike weight, standard error for the WAIC computations and for the difference with the WAIC for the top-ranked model. RH stands for reaction to humans.

In our study, none of the subjects could spontaneously use a 2-step strategy to solve the first condition of this task. To avoid a decrease in motivation and ensure the participation of wild individuals, we refrained from administering more trials in this condition. However, it is possible that some individuals would have mastered this task, if given more time. Another possibility, however, is that 2-step strategies are cognitively very demanding and beyond the ability of our study taxon. Indeed, evidence of spontaneous innovation in multi-step problems is to date limited to very few species like great apes ${ }^{28,92-94}$, parrots and corvids $s^{53,95-100}$. In line with this, evidence of innovation was found in all the other conditions in which 1-step strategies were required.

Our study further revealed inter-individual differences in innovation rate, which largely depended on the behavioural strategy used during the task. The probability to innovate was higher when subjects showed shorter latencies to interact with the box (with females having longer latencies) and a higher proportion of functional manipulations (in line with our predictions; see Table 1). These results suggest that manipulating the functional parts of the foraging boxes (rather than manipulating the box in general) was a better predictor of innovation in wild Barbary macaques. One may speculate that macaques did not simply obtain food by blindly exploring the box, but focused on the functional parts of it to solve the task. If this was the case, subjects unlikely relied on colour to detect the functional parts of the boxes, as they did not transfer their knowledge across conditions (i.e., in which different functional parts were coloured in the same way). However, it is also possible that, as functional manipulations were necessary to solve the task, individuals simply explored the boxes randomly, but only when they happened to explore the functional parts, the boxes got open. Unfortunately, our data do not allow us to differentiate between these two explanations.

Overall exploration of the box (i.e. including manipulation of non-functional parts), in contrast, did not predict innovation. In the past, studies on innovation have found a positive relationship between exploration and innovation in captive primates ${ }^{20}$ and other species (e.g. birds ${ }^{20,53,56,59}$, carnivores ${ }^{38,39}$; see $^{2}$ ). Differences with previous studies, however, can be easily explained by the fact that exploration has been often operationalized in different ways (e.g. number of different exploratory or functional behaviours during the innovation task, number of different objects/tasks manipulated during other tasks, time spent interacting with the box ${ }^{18,19}$ ). Even more importantly, most previous studies on innovation have not differentiated between functional and non-functional manipulations of the testing boxes ${ }^{18}$.

Interestingly, individuals showed no consistency across tasks, with some monkeys innovating in one condition, but failing to solve the others. This result is interesting for several reasons. Firstly, it confirms that the contingent behavioural strategies used, rather than specific characteristics of the subject (e.g. sex, age, rank, centrality, neophobia, reaction to humans), determine whether the subject will be successful in a specific task. However, it should be noted that more precise measures of reaction to humans (e.g., exposing monkeys to more novel humans, instead of just one, as we did in this study) might have provided different results. Secondly, our study suggests that there are no consistent individual differences in how likely animals are to innovate. Rather, individuals may come up with the correct behavioural strategy in one context, but fail to do the same in other contexts. Therefore, the ability to innovate may be context-dependent, as has been proposed for neophobia ${ }^{101}$. This would also explain why studies on innovation often provide contrasting results on the effect of individual characteristics on innovation ${ }^{18}$. Moreover, these results suggest that innovation may be spread across conspecifics regardless of their individual characteristics. Finally, our results suggest that macaques may have little ability to generalize 

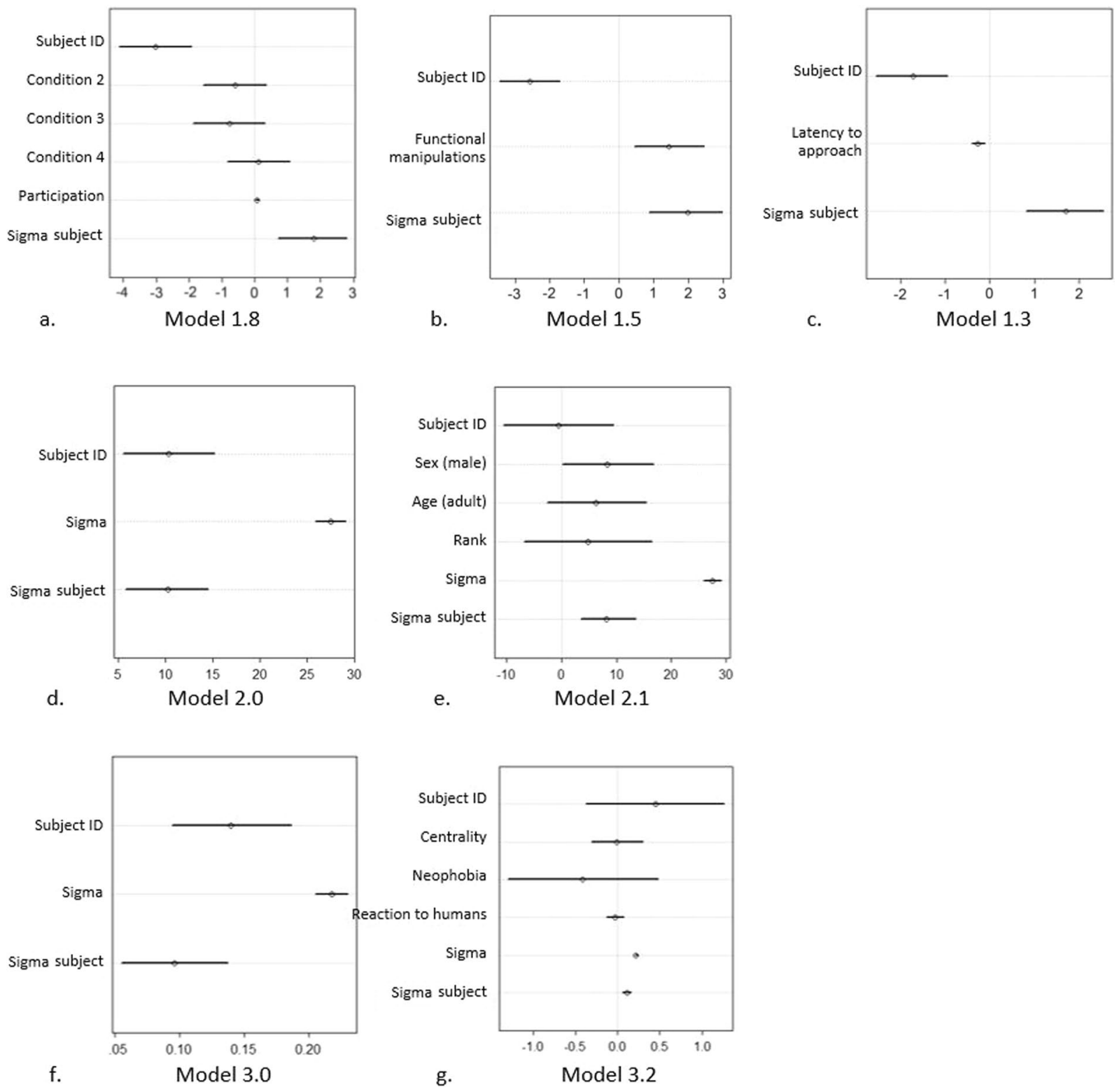

Figure 5. For each set of models, estimates of the best models: (a) M1.8, (b) M1.5 and (c) M1.3; (d) M2.0 and (e) M2.1; and (f) M3.0 and (g) M3.2 (see Table 3 for more details).

across contexts. Across conditions, functional parts of the box were always painted with the same colour, but this cue was not used by macaques to perform functional manipulations across conditions.

The probability of showing inhibitory problems (i.e. directly trying to reach for food through the transparent parts of the foraging box) had no effect on innovation rate (see Table 1). In this study, innovation was operationalized as the solution to a novel problem, in that individuals had to interact with a novel foraging box to reach for food. However, innovation can also imply the novel solution to a familiar problem ${ }^{1,2}$, which requires the inhibition of old strategies when they become inefficient ${ }^{24}$. Therefore, it is possible that inhibitory levels predict innovation only in the second kind of tasks, or when the solution of the task requires planning ${ }^{28}$, as inhibitory demands are higher ${ }^{102}$.

Similarly, the probability to innovate was not related to the presence of others. These results suggest that social facilitation played no important role in this task, in contrast to our predictions (see Table 1). Some studies, for instance, have shown that the mere presence of conspecifics might have a positive effect on individuals' tendency to innovate, even when individuals are not actively learning innovative solutions from others. In particular, the presence of conspecifics may encourage individuals to be less neophobic and more exploratory, both in primates ${ }^{103,104}$ and other species (e.g. birds ${ }^{73,105}$, fish ${ }^{106}$; see $^{102}$ ). Given that social facilitation is probably highly context-dependent ${ }^{107,108}$, more studies are needed to understand whether the cognitive demands of this task or other factors explained the lack of social facilitation in this study. For instance, it is possible that macaques' participation in the task (rather than successful performance) might be affected by the presence of others at the 
boxes. In the future, studies should better disentangle whether and how exactly others affect participation and performance in innovation tasks.

Overall, our results provide no support to existing evolutionary hypotheses on the emergence of innovation, and only partly confirm previous studies on innovation in captive primates and other taxa. In this respect, they importantly contribute to our understanding of innovation, by extending a consolidated experimental approach to the study of wild primates. To provide a more stringent test of current evolutionary hypotheses on the emergence of innovation and better understand the evolutionary origins of human innovation, it will be especially important to conduct more studies on innovation in wild primates. In particular, future studies will need to include a higher number of individuals in different captive conditions, to allow direct comparisons between wild and captive conspecifics, and better understand the role played by captivity on the ability to innovate. Moreover, future studies should include more species tested with the same procedures, to directly compare how the socio-ecological characteristics of a species affect innovation. Particularly interesting would be the comparison of different macaque species, to understand whether rank or centrality play different roles depending on the species dominance styles ${ }^{109,110}$. Furthermore, inter- and intra-specific comparisons on innovation should ideally use multiple foraging tasks, to further assess consistency across tasks, and better understand the role played by inhibition on the ability to innovate. Integrating the study of social behaviour to the investigation of innovation will surely provide novel insights into this fascinating but still overlooked topic.

\section{Data availability}

All data are available as supplementary material.

Received: 9 December 2019; Accepted: 2 March 2020;

Published online: 12 March 2020

\section{References}

1. Ramsey, G., Bastian, M. L. \& van Schaik, C. Animal innovation defined and operationalized. Behavioral and Brain Sciences 30, 393-437 (2007).

2. Reader, S. M. \& Laland, K. N. Animal innovation. (Oxford University Press, New York, NY, 2003).

3. van der Leeuw, S. \& Torrence, R. What's new? London, U.K.: Unwin Hyman (1989).

4. O'Brien, M. J. \& Shennan, S. J. Innovation in cultural systems. MIT Press (2010).

5. Berger, J., Swenson, J. E. \& Persson, I. L. Recolonizing carnivores and naïve prey: Conservation lessons from pleistocene extinctions. Science 291, 1036-1039 (2001).

6. Brooker, M. L., Davies, N. B. \& Noble, D. G. Rapid decline of host defences in response to reduced cuckoo parasitism: Behavioural flexibility of reed warblers in a changing world. Proceedings of the Royal Society B 265, 1277-1282 (1998).

7. Estes, J. A., Tinker, M. T., Williams, T. M. \& Doak, D. F. Killer whale predation on sea otters linking oceanic and nearshore ecosystems. Science 282, 473-476 (1998).

8. Laland, K. N. A theoretical investigation of the role of social transmission in evolution. Ethology and Sociobiology 13, 87-113 (1992).

9. Lee, P. C. Adaptations to environmental change: An evolutionary perspective. In H. O. Box (Ed.), Primate responses to environmental change (pp. 39-56). New York, NY: Chapman \& Hall (1991).

10. Nicolakakis, N., Sol, D. \& Lefebvre, L. Behavioural flexibility predicts species richness in birds, but not extinction risk. Animal Behaviour 65, 445-452 (2003).

11. Sol, D. Behavioural flexibility: A neglected issue in the ecological and evolutionary literature. In S. M. Reader, \& K. N. Laland (Eds.), Animal innovation (pp. 63-82). New York, NY: Oxford University Press (2003).

12. Sol, D., Duncan, R. P., Blackburn, T. M., Cassey, P. \& Lefebvre, L. Big brains, enhanced cognition, and response of birds to novel environments. Proceedings of the National Academy of Sciences 102, 5460-5465 (2005).

13. Sol, D., Lefebvre, L. \& Rodríguez-Teijeiro, J. D. Brain size, innovative propensity and migratory behaviour in temperate Palaearctic birds. Proceedings of the Royal Society B 272, 1433-1441 (2005).

14. Sol, D., Timmermans, S. \& Lefebvre, L. Behavioral flexibility and invasion success in birds. Animal Behaviour 60, 495-502 (2002).

15. Wyles, J. S., Kunkel, J. G. \& Wilson, A. C. Birds, behaviour, and anatomical evolution. Proceedings of the National Academy of Sciences 80, 4394-4397 (1983).

16. Dukas, R. \& Bernays, E. A. Learning improves growth rate in grasshoppers. Proceedings of the National Academy of Sciences $\mathbf{9 7}$, 2637-2640 (2000).

17. Lefebvre, L. Taxonomic counts of cognition in the wild. Biology Letters 7, 631-633 (2011).

18. Amici, F., Lehmann, J., Widdig, A. \& Majolo, B. A meta-analysis of inter-individual differences in innovation. Animal Behaviour 155, 257-268 (2019).

19. Griffin, A. S. \& Guez, D. Innovation and problem solving: A review of common mechanisms. Behavioural Processes 109, 121-134 (2014).

20. Day, R. L., Coe, R. L., Kendal, J. R. \& Laland, K. N. Neophilia, innovation and social learning: A study of intergeneric differences in callitrichid monkeys. Animal Behaviour 65, 559-571 (2003).

21. Dean, L. G., Hoppitt, W., Laland, K. N. \& Kendal, R. L. Sex ratio affects sex-specific innovation and learning in captive ruffed lemurs (Varecia variegate and Varecia rubra). American Journal of Primatology 73, 1210-1221 (2011).

22. Hrubesch, C., Preuschoft, S. \& van Schaik, C. Skill mastery inhibits adoption of observed alternative solutions among chimpanzees (Pan troglodytes). Animal Cognition 12, 209-216 (2009).

23. Köhler, W. The Mentality of Apes. (Harcourt Brace, New York, NY, 1925).

24. Manrique, H. M., Völter, C. J. \& Call, J. Repeated innovation in great apes. Animal Behaviour 85, 195-202 (2013).

25. Povinelli, D. J. Folk Physics For Apes: The Chimpanzee's Theory of How The World Works. (Oxford University Press, New York, NY, 2000).

26. Santos, L. R., Pearson, H. M., Spaepen, G. M., Tsao, F. \& Hauser, M. D. Probing the limits of tool competence: Experiments with two non-tool-using species (Cercopithecus aethiops and Saguinus oedipus). Animal Cognition 9, 94-109 (2006).

27. Visalberghi, E., Fragaszy, D. M. \& Savage-Rumbaugh, S. Performance in a tool-using task by common chimpanzees (Pan troglodytes), bonobos (Pan paniscus), an orangutan (Pongo pygmaeus), and capuchin monkeys (Cebus apella). Journal of Comparative Psychology 109, 52-60 (1995).

28. Völter, C. J. \& Call, J. Younger apes and human children plan their moves in a maze task. Cognition 130, 186-203 (2014).

29. Powell, L. E., Isler, K. \& Barton, R. A. Re-evaluating the link between brain size and behavioural ecology in primates. Proceedings of the Royal Society B 284, 1865 (2017). 
30. Kummer, H. \& Goodall, J. Conditions of innovative behaviour in primates. Philosophical Transactions of the Royal Society B 308, 203-214 (1985).

31. Laland, K. N. \& Reader, S. M. Foraging innovation in the guppy. Animal Behaviour 57, 331-340 (1999).

32. Reader, S. M. \& Laland, K. N. Primate innovation: Sex, age, and social rank differences. International Journal of Primatology 22, 787-805 (2001).

33. Melin, A. D., Young, H. C., Mosdossy, K. N. \& Fedigan, L. M. Seasonality, extractive foraging and the evolution of primate sensorimotor intelligence. Journal of Human Evolution 71, 77-86 (2014).

34. Turner, S. E., Fedigan, L. M., Matthews, H. D. \& Nakamichi, M. Disability, compensatory behavior, and innovation in free-ranging adult female Japanese macaques (Macaca fuscata). American Journal of Primatology 74, 788-803 (2012).

35. Boogert, N. J., Reader, S. M. \& Laland, K. N. The relation between social rank, neophobia and individual learning in starlings. Animal Behaviour 72, 1229-1239 (2006).

36. Gajdon, G. K., Fijn, N. \& Huber, L. Testing social learning in a wild mountain parrot, the kea (Nestor notabilis). Animal Learning \& Behavior 32, 62-71 (2004).

37. Gajdon, G. K., Fijn, N. \& Huber, L. Limited spread of innovation in a wild parrot, the kea (Nestor notabilis). Animal Cognition 9 , 173-181 (2006).

38. Benson-Amram, S. \& Holekamp, K. E. Innovative problem solving by wild spotted hyenas. Proceedings of the Royal Society B 279, 4087-4095 (2012).

39. Benson-Amram, S., Weldele, M. L. \& Holekamp, K. E. A comparison of innovative problem-solving abilities between wild and captive spotted hyaenas, Crocuta crocuta. Animal Behaviour 85, 349-356 (2013).

40. Laidre, M. E. Spontaneous performance of wild baboons on three novel food-access puzzles. Animal Cognition 11, 223-230 (2008).

41. de Moura, A. C. \& Lee, P. C. Wild capuchins show male-biased feeding tool use. International Journal of Primatology 31, 457-470 (2010).

42. Berkman, L.F. \& Glass, T. Social integration, social networks, social support and health. In: L. F. Berkman, \& I. Kawachi (Eds.), Social epidemiology (pp. 158-162). New York, NY: Oxford University Press (2000).

43. Holt-Lunstad, J., Smith, T. B. \& Layton, J. B. Social relationships and mortality risk: a meta-analytic review. PLoS Medicine 7, e1000316 (2010)

44. Kulik, L., Muniz, L., Mundry, R. \& Widdig, A. Patterns of interventions and the effect of coalitions and sociality on male fitness. Molecular Ecology 21, 699-714 (2012).

45. Langergraber, K., Mitani, J., Watts, D. \& Vigilant, L. Male-female socio-spatial relationships and reproduction in wild chimpanzees. Behavioral Ecology and Sociobiology 67, 861-873 (2013).

46. Schülke, O., Bhagavatula, J., Vigilant, L. \& Ostner, J. Social bonds enhance reproductive success in male macaques. Current Biology 20, 2207-2210 (2010)

47. Silk, J. B., Alberts, S. C. \& Altmann, J. Social bonds of female baboons enhance infant survival. Science 302, 1231-1234 (2003).

48. Silk, J. B. et al. The benefits of social capital: close social bonds among female baboons enhance offspring survival. Proceedings of the Royal Society B 276, 3099-3104 (2009).

49. Silk, J. B. et al. Strong and consistent social bonds enhance the longevity of female baboons. Current Biology 20, 1359-1361 (2010).

50. Farine, D. R. A guide to null models for animal social network analysis. Methods in Ecology and Evolution 8, 1309-1320 (2017).

51. Fruteau, C., Voelkl, B., van Damme, E. \& Noe, R. Supply and demand determine the market value of food providers in wild vervet monkeys. Proceedings of the National Academy of Sciences 106, 12007-12012 (2009).

52. Kulahci, I. G., Ghazanfar, A. A. \& Rubenstein, D. I. Knowledgeable lemurs become more central in social networks. Current Biology 28, 1306-1310 (2018)

53. Auersperg, A. M. I., von Bayern, A. M. P., Gajdon, G. K., Huber, L. \& Kacelnik, A. Flexibility in problem solving and tool use of kea and New Caledonian crows in a multi access box paradigm. PLoS One 6, e20231 (2011).

54. Carter, A. J., Marshall, H. H., Heinsohn, R. \& Cowlishaw, G. How not to measure boldness: Novel object and antipredator responses are not the same in wild baboons. Animal Behaviour 84, 603-609 (2012a).

55. Carter, A., Marshall, H., Heinsohn, R. \& Cowlishaw, G. Evaluating animal personalities: Do observer assessments and experimental tests measure the same thing? Behavioral Ecology and Sociobiology 66, 153-160 (2012b).

56. Greenberg, R. The role of neophobia and neophilia in the development of innovative behaviour in birds. In R. Greenberg, S. M. Reader, \& K. N. Laland (Eds.), Animal innovation (pp. 175-196). New York, NY: Oxford University Press (2003).

57. Guenther, A., Brust, V., Dersen, M. \& Trillmich, F. Learning and personality types are related in cavies (Cavia aperea). Journal of Comparative Psychology 128, 74-81 (2014).

58. Massen, J. J. M., Antonides, A., Arnold, A. M. K., Bionda, T. \& Koski, S. A behavioral view on chimpanzee personality: Exploration tendency, persistence, boldness, and tool-orientation measured with group experiments. American Journal of Primatology 75, 947-958 (2013).

59. Overington, S. E., Cauchard, L., Coté, K. A. \& Lefebvre, L. Innovative foraging behaviour in birds: What characterizes an innovator? Behavioural Processes 87, 274-285 (2011).

60. Webster, S. J. \& Lefebvre, L. Problem solving and neophobia in a columbiform-passeriform assemblage in Barbados. Animal Behaviour 62, 23-32 (2001).

61. Exnerová, A., Svádová, K. H., Fucíková, E., Drent, P. \& Stys, P. Personality matters: individual variation in reactions of naive bird predators to aposematic prey. Proceedings of the Royal Society B 277, 723-728 (2010).

62. Jones, R. B., Mills, A. D. \& Faure, J. M. Genetic and experiential manipulation of fear-related behavior in Japanese quail chicks (Coturnix coturnix japonica). Journal of Comparative Psychology 105, 15-24 (1991)

63. Verbeek, M. E. M., Drent, P. J. \& Wiepkema, P. R. Consistent individual differences in early exploratory behaviour of male great tits. Animal Behaviour 48, 1113-1121 (1994).

64. Damerius, L. A. et al. Orientation toward humans predicts cognitive performance in orangutans. Scientific Reports 7, 40052 (2017).

65. Hardus, M. E., Lameira, A. R., van Schaik, C. P. \& Wich, S. A. Tool use in wild orangutans modifies sound production: a functionally deceptive innovation? Proceedings of the Royal Society B 276, 3689-3694 (2009).

66. Hosey, G., Jacques, M. \& Pitts, A. Drinking from tails: Social learning of a novel behaviour in a group of ring-tailed lemurs (Lemur catta). Primates 38, 415-422 (1997).

67. Perry, S. E., Barrett, B. J. \& Godoy, I. Older, sociable capuchins (Cebus capucinus) invent more social behaviors, but younger monkeys innovate more in other contexts. Proceedings of the National Academy of Sciences 114, 7806-7813 (2017).

68. van Schaik, C. P. et al. The reluctant innovator: orangutans and the phylogeny of creativity. Philosophical Transactions of the Royal Society B 371, 371 (2016).

69. Bastian, M. L., van Noordwijk, M. A. \& van Schaik, C. P. Innovative behaviors in wild Bornean orangutans revealed by targeted population comparison. Behaviour 149, 275-297 (2012).

70. van Schaik, C. P., van Noordwijk, M. A. \& Wich, S. A. Innovation in wild Bornean orangutans (Pongo pygmaeus wurmbii). Behaviour 143, 839-876 (2006).

71. Boogert, N. J., Monceau, K. \& Lefebvre, L. A field test of behavioural flexibility in Zenaida doves (Zenaida aurita). Behavioural Processes 85, 135-141 (2010).

72. Morand-Ferron, J., Cole, E. F., Rawles, J. E. C. \& Quinn, J. L. Who are the innovators? A field experiment with 2 passerine species. Behavioral Ecology and Sociobiology 22, 1241-1248 (2011). 
73. Morand-Ferron, J. \& Quinn, J. L. Larger groups of passerines are more efficient problem solvers in the wild. Proceedings of the National Academy of Sciences 108, 15898-15903 (2011).

74. Morand-Ferron, J., Lefebvre, L., Reader, S. M., Sol, D. \& Elvin, S. Dunking behaviour in Carib grackles. Animal Behaviour 68, $1267-1274(2004)$

75. Thornton, A. \& Samson, J. Innovative problem solving in wild meerkats. Animal Behaviour 83, 1459-1468 (2012).

76. Huebner, F. \& Fichtel, C. Innovation and behavioral flexibility in wild red-fronted lemurs (Eulemur ruffrons). Animal Cognition 18, 777-787 (2015)

77. Bouchard, J., Goodyer, W. \& Lefebvre, L. Social learning and innovation are positively correlated in pigeons (Columba livia). Animal Cognition 10, 259-266 (2007).

78. Boesch, C. What makes us human (Homo sapiens)? The challenge of cognitive cross-species comparison. Journal of Comparative Psychology 121, 227-240 (2007).

79. Ryan, M. J. Replication in field biology: The case of the frog eating bat. Science 334, 1229-1230 (2011)

80. Call, J. \& Tomasello, M. The effect of humans on the cognitive development of apes. In A. E. Russon, K. A. Bard, \& S. T. Parker (Eds.), Reaching into thought: the minds of the great apes (pp. 371-403). New York, NY: Cambridge University Press (1996).

81. Tomasello, M. \& Call, J. Assessing the validity of ape-human comparisons: A reply to Boesch (2007). Journal of Comparative Psychology 122, 449-452 (2008).

82. Bergman, T. J. \& Kitchen, D. M. Comparing responses to novel objects in wild baboons (Papio ursinus) and geladas (Theropithecus gelada). Animal Cognition 12, 63-73 (2009).

83. Greenberg, R. Differences in feeding neophobia in the tropical migrant wood warblers Dendroica castanea and D. pensylvanica. Journal of Comparative Psychology 98, 131-136 (1984).

84. Huber, L. \& Gajdon, G. K. Technical intelligence in animals: The kea model. Animal Cognition 9, 295-305 (2006).

85. Neumann, C. et al. Assessing dominance hierarchies: validation and advantages of progressive evaluation with Elo-rating. Animal Behaviour 82, 911-921 (2011).

86. Oksanen, J. et al. vegan: Community Ecology Package. R package version 2.5-3 (2018).

87. Farine, D. R. asnipe: Animal social network inference and permutations for ecologists. R package version 1.1.10 (2018).

88. Csardi, G. \& Nepusz, T. The igraph software package for complex network research. Inter Journal, Complex Systems 1695 (2006).

89. Farine, D. R. \& Whitehead, H. Constructing, conducting, and interpreting animal social network analysis. Journal of Animal Ecology 84, 1144-1163 (2015).

90. McElreath, R. Rethinking: statistical rethinking book package. R package version 1.72 (2016)

91. Stan Development Team RStan: the R interface to Stan. R package version 2.19.2. http://mc-stan.org/ (2019).

92. Carvalho, S., Cunha, E., Sousa, C. \& Matsuzawa, T. Chaînes opératoires and resource-exploitation strategies in chimpanzee (Pan troglodytes) nut cracking. Journal of Human Evolution 55, 148-163 (2008)

93. Carvalho, S., Biro, D., McGrew, W. C. \& Matsuzawa, T. Tool-composite reuse in wild chimpanzees (Pan troglodytes): archaeologically invisible steps in the technological evolution of early hominins? Animal Cognition 12, 103-114 (2009).

94. Whiten, A., Custance, D. M., Gomez, J. C., Teixidor, P. \& Bard, K. A. Imitative learning of artificial fruit processing in children (Homo sapiens) and chimpanzees (Pan troglodytes). Journal of Comparative Psychology 110, 3-14 (1996).

95. Auersperg, A. M. I., Kacelnik, A. \& von Bayern, A. M. P. Explorative learning and functional inferences on a five-step meansmeans-end problem in Goffin's cockatoos (Cacatua goffini). PLoS One 8, e68979 (2013).

96. Bird, C. D. \& Emery, N. J. Insightful problem solving and creative tool modification by captive rooks. Proceedings of the National Academy of Sciences 106, 10370-11037 (2009).

97. Hunt, G. R. Manufacture and use of hook-tools by New Caledonian crows. Nature 379, 249-251 (1996).

98. Miyata, H., Gajdon, G. K., Huber, L. \& Fujita, K. How do kea (Nestor notabilis) solve artificial fruit problems with multiple locks. Animal Cognition 14, 45-58 (2010).

99. Taylor, A. H., Hunt, G. R., Holzhaider, J. C. \& Gray, R. D. Spontaneous metatool use by New Caledonian crows. Current Biology 17, 1504-1507 (2007).

100. Wimpenny, J. H., Weir, A. S., Clayton, L., Rutz, C. \& Kacelnik, A. Cognitive processes associated with sequential tool use in New Caledonian crows. PLoS One 4, e6471 (2009).

101. Mettke-Hofmann, C. Context-specific neophilia and its consequences for innovations. Behavioral and Brain Sciences 30, 419-420 (2007).

102. Brosnan, S. F. \& Hopper, L. M. Psychological limits on animal innovation. Animal Behaviour 92, 325-332 (2014).

103. Dindo, M., Whiten, A. \& de Waal, F. B. M. In-group conformity sustains different foraging traditions in capuchin monkeys (Cebus apella). PLoS One 4, e7858 (2009).

104. Stewart, A. M. E., Gordon, C. H., Wich, S. A., Schroor, P. \& Meijaard, E. Fishing in Macaca fascicularis: A rarely observed innovative behavior. International Journal of Primatology 29, 543-548 (2008).

105. Dukas, R. \& Kamil, A. C. The cost of limited attention in blue jays. Behavioral Ecology 11, 502-506 (2000).

106. Day, R. L., MacDonald, T., Brown, C., Laland, K. N. \& Reader, S. M. Interactions between shoal size and conformity in guppy social foraging. Animal Behaviour 62, 917-925 (2001).

107. Fragaszy, D. \& Visalberghi, E. Recognizing a swan: Socially-biased learning. Psychologia 44, 82-98 (2001).

108. Griffin, A. S., Lermite, F., Perea, M. \& Guez, D. To innovate or not: Contrasting effects of social groupings on safe and risky foraging in Indian mynahs. Animal Behaviour 86, 1291-1300 (2013).

109. Thierry, B. Unity in diversity: Lessons from macaque societies. Evolutionary Anthropology: Issues, News, and Reviews 16, 224-238 (2007).

110. Thierry, B. et al. The social repertoire of Sulawesi macaques. Primate Research 16, 203-226 (2000).

\section{Acknowledgements}

We are grateful to Eric Shaw at the Helping Hand Trust in Gibraltar for his permission to conduct research on the wild group of macaques, and to Montserrat Colell for endless support. Federica Amici was financed by a German Research Foundation (DFG) research grant (AM 409/4-1) during this study. We are grateful to the University of Leipzig and the Max-Planck Institute for Evolutionary Anthropology for support during this study. We acknowledge support from the German Research Foundation (DFG) and Leipzig University within the program of Open Access Publishing.

\section{Author contributions}

F.A. designed and coordinated the study, with extensive input by A.W. and B.M. A.L.C. collected the data. F.A. coded the data, carried out the statistical analyses and wrote the M.S., with substantial input by all the other coauthors. All authors reviewed the manuscript. 


\section{Competing interests}

None of the authors declares any competing financial and non-financial interests. The authors have no competing interests as defined by Nature Research, or other interests that might be perceived to influence the results and/or discussion reported in this paper.

\section{Additional information}

Supplementary information is available for this paper at https://doi.org/10.1038/s41598-020-61558-2.

Correspondence and requests for materials should be addressed to F.A.

Reprints and permissions information is available at www.nature.com/reprints.

Publisher's note Springer Nature remains neutral with regard to jurisdictional claims in published maps and institutional affiliations.

(c) (i) Open Access This article is licensed under a Creative Commons Attribution 4.0 International License, which permits use, sharing, adaptation, distribution and reproduction in any medium or format, as long as you give appropriate credit to the original author(s) and the source, provide a link to the Creative Commons license, and indicate if changes were made. The images or other third party material in this article are included in the article's Creative Commons license, unless indicated otherwise in a credit line to the material. If material is not included in the article's Creative Commons license and your intended use is not permitted by statutory regulation or exceeds the permitted use, you will need to obtain permission directly from the copyright holder. To view a copy of this license, visit http://creativecommons.org/licenses/by/4.0/.

(c) The Author(s) 2020 